\title{
La cultura como horizonte. Entre la tradición y la modernidad
}

\section{Henrique Urbano}

En los espacios latinoamericanos donde la modernidad es un vocablo ambiguo y de uso indigesto, tratar de ubicar los problemas relacionados con la cultura es tarea casi imposible (1). Son muchos los obstáculos. Y el más sobresaliente es la ignorancia, siendo la banalidad, su acicate. Pero, si se trata de sopesar el alcance del lenguaje y lo que los términos empleados en el análisis de los hechos pueden expresar, la modernidad es algo más que una sencilla palabra de uso común y corriente. Es compleja y polifacética. $Y$ si bien es cierto todas las realidades sociohistóricas presentan su qué de opacidad, no es menos cierto también que la mirada puede penetrarlas en la medida en que ellas se pliegan a las razones empleadas por el discurso indagador. Como lo señaló Octavio Paz, en América Latina no se dieron las circunstancias históricas que, en Europa, abonaron la eclosión de la crítica filosófica donde echó raíces la modernidad (2). Y si es así, la cultura que fue el caldo de cultivo del discurso filosófico y sociológico de la modernidad tampoco tuvo lugar. Hablemos, en primer lugar, de la cultura.

\section{I \\ La cultura como horizonte}

En las últimas décadas no son pocas las dificultades que se plantearon en torno a la definición de la idea de cultura. EI siglo XIX nos había lejado una orientación tanto académica como científica que parecía suficientemente sólida para resistir a los asaltos de los cambios acaecidos en las sociedades contemporáneas. Sin embargo, a partir de la segunda mitad del siglo $X X$, más precisamente terminada la Segunda Gran Guerra Mundial, allá por los años 1950, las cosas tomaron nuevos rumbos y fenómenos sociales de gran envergadura cuestionaron algunas de las concepciones que eran de uso corriente en Ciencias Humanas[3]. Y una de ellas se refería precisamente al campo de la cultura. No son hechos que acaecieron de la noche para la mañana. Más bien han sido prácticas innovadoras que a partir de ángulos diferentes ampliaron lo que en gérmen contenia lo que suele definirse por modernidad. "La madre de todos los cambios" tiene ahí su nido. Porque en ella se incubó la gran mayoria de las ideas que hoy guian y echan luz sobre los cambios y también sobre los trastornos que habitan las sociedades contemporáneas. 
En los albores de las Ciencias Humanas, "cultura" designaba, de una manera general, las obras salidas de las manos del hombre. A ella se acogió lo que serían, con el discurso del tiempo, las Ciencias antropológicas, para reflexionar sobre las estructuras simbólicas de las sociedades, mayormente las arcaicas y antiguas. Por extensión, o quizá por razones de práctica científica, se ha puesto énfasis en la expresión de totalidad o en el enfoque global que la idea de cultura sugeria. En Alemania, por ejemplo, tuvo gran difusión lo que solía llamarse las "ciencias de la cultura" por razones de orden filosófico. ¿Quién no recuerda las obras de Alfred Weber, y más cercanos a nuestros días, los sugestivos ensayos de Karl Manheim sobre la sociologia de la cultura?(4) Eran el tiempo de las "sociologias del espíritu", expresión que suena a los oidos de la sociedad contemporánea como algo extraño y lejano. Empero, las "ciencias del espiritu" o "las ciencias de la cultura" como les llamaba Ernest Cassirer en su Zur Logik der Kulturuwissenschaften (1941) eran el marco donde se definian las orientaciones metodológicas para el estudio del hombre y de su "circunstancia", como diria Ortega y Gasset.

En el ambiente anglosajón, particularmente en los medios académicos de Estados Unidos, la palabra "cultura" guardaba cierta semblanza con las orientaciones que acabo de recordar. No hay mejor ejemplo de ello que el libro de Ruth Benedict, Patterns of Culture, El hombre y la cultura. El camino le habia sido abierto por Franza Boas que desde los primeros años del siglo $X X$ definía la cultura en su libro The Mind of Primitive Man (1911) como "la totalidad de las reacciones y actividades mentales y fisicas que caracterizan la conducta de los individuos componentes de un grupo social, colectiva e individualmente, en relación a su ambiente natural, a otros grupos, a miembros del mismo grupo y de cada individuo hacia si mismo"(5). Tenia Boas presente la definición que le habia servido E.B. Tylor, en The Primitive Culture (1871) : "La cultura o civilización, en sentido etnográfico amplio, es aquel todo complejo que incluye el conocimiento, las creencias, el arte, la moral, el derecho, las costumbres y cualesquiera otros hábitos o capacidades adquiridos por el

(4) Karl Manheim, Ensayos de sociologia de ta cullura, Aguilar, Madrid, 1963 (5) Franz Boas, Cuestiones fundamentales de antropologia cultural. Lautaro. Buenos Aires, 1947 hombre en cuento miembro de la sociedad". Sin embargo, el giro dado a las carreras universitarias terminaron por anquilozarla y meterla en una camisa de siete varas.

En el mundo intelectual de Francia y en los arrabales de la cultura francesa, constituidos por la red de sociedades que adoptaron esa lengua como lengua materna, no faltaron autores para discutir y diseñar lo que se entendía por "cultura" y dar a la noción un no sé qué de preciosidad. Hay varias señales de esa preocupación y de las orientaciones que los autores y escuelas les dieron. Y no todas emplean la palabra "cultura", aunque, en el fondo es de ella que hablan. Un ejemplo. Las definiciones de Emile Durkheim (1868-1917) de "representación colectiva" o "conciencia colectiva"(6). De igual manera, y en la misma línea de tradición sociológi$\mathrm{ca}$, las reflexiones de Maurice Halbwachs (1877-1945) sobre "el marco social de la memoria"(7). Los dos sociólogos hablan de lo que se podria llamar "el mundo de los valores". Y más precisamente en el caso de Halbawchs, las representaciones sociales en el marco del patrimonio, es decir la memoria de un grupo, como por ejemplo, una familia con alcurnia o hasta sin ella. La idea que subyace a esas nociones es la de una configuración de imágenes o símbolos que pueden ser más o menos estructurados en forma de sistema de ideas o de figuras. Durkheim insistía en la capacidad que tenían esas ideas o representaciones colectivas en imponerse y dictar su fuerza persuasiva. Era su marca distintiva.

De cierto modo, esa orientación general de la tradición socioantropológica francesa siguió su camino y autores contemporáneos como Pierre Bourdieu se inscriben en esa orden de ideas, pese a sus deudas filosóficas con Heidegger. Su noción de habitus recupera lo que Durkheim pretendía definir con la noción de "representación colectiva", es decir la existencia de lo que llamé hace poco de conjuntos más o menos lógicos y sistemáticos de valores o de ideas (8). Quizá la palabra "configuración" definiria mejor esos hechos sistemáticos. Se podria afirmar, por ejemplo, que el burgués europeo del siglo XIX se regia por un habitus en que predomi(6) Emile Durkheim, Sociologie et philosophie. PUF, Paris, 1996 (1924). (7) Maurice Halbwachs, Les cadres sociaux de la memoire, PUF Paris, 1964. (8) Pierre Bourdieu, Le sens pratique. Minuit, Paris.1980; Science de la science et reflexivite, Raisons d'agir, Paris, 2001. 
naban las herencias culturales revolucionarias y liberales del siglo XVIII y la primacía de actuar capitalista, proclive a la expansión industrial y a la difusión del capital. O retomando los estudios de Max Weber, hablar del habitus protestante que, al fin y al cabo, desemboca en forma peculiar de práctica capitalista definida en el ámbito de una configuración de ideas o valores religiosos. Cuando Bourdieu define un campo simbólico y su importancia en la comprensión de las sociedades contemporáneas, no se refiere a hechos sociológicos distintos de lo que tradicionalmente se entiende por cultura. En ese sentido, tanto la noción de habitus como luego la de campo religioso o campo simbólico comparten las mismas características que generalmente se atribuyen al mundo de la cultura.

Fernand Dumont puede ser uno de los grandes maestros en el terreno de la comprensión de los hechos de cultura. Y no le faltan también los rasgos de lo que se podría considerar las huellas del instinto sociológico de Durkheim. La distinción que Dumont establece entre cultura primera y cultura segunda, sin ser nociones con rigores de conceptos operativos, ayudan a comprender to que son las grandes configuraciones simbólicas, primero, en lo que ellas tienen de difuso, y luego en la forma como ellas definen la práctica social o individual (9). No sé si abuso de una comparación para dar a las dos nociones de Dumont una interpretación más directa. Pero la cultura primera es para la cultura segunda, lo que en el vocabulario de Ferdinand de Saussure, la idea de sistema es para los actos de habla. La lengua posee sus reglas sistemáticas las cuales se actualizan precisamente cuando un individuo las pone en práctica a través del habla. De esa manera, la cultura primera es como la configuración general que imprime a la cultura segunda sus reglas y le dicta sus normas prácticas.

Fue también Dumont que enmarcó el debate sobre la cultura en la distancia que va del medio físico al imaginario donde se inscriben todos los hechos de cultura. En otras palabras, la cultura es ese horizonte a partir del cual el hombre contemporáneo puede hablar del medio, de si mismo y de los otros individuos. Ahora bien, hay varios discursos o lenguajes que se enfren-

(9) Fernand Dumont, Le lieu de l'homme La culture comme distance el mómoire, HMH, Montreal, 1968; Le sort de la culture, L'Héxagone, Montreal, 1987. tan en la expresión de ese horizonte. Entre ellos, los de las Ciecncias humanas, que tratan de legitimizar a través de procesos objetivos o similares, lo que es el hombre y su medio. Lo que él llamaba cultura primera se proyecta en una cultura segunda, o se encarna en los distintos lenguajes del campo socioantropológico. Ocurre, sin embargo, que otras formas de lenguaje actúan en la construcción de la cultura primera. La televisión, por ejemplo, ejerce sobre el imaginario una acción eficaz. Con ella y con los otros instrumentos de los media, el horizonte cultural se ve turbado para otorgar a la cultura segunda los elementos de un discurso preciso y significativo. Sería esa razón que podría explicar el narcisismo de la cultura contemporánea en la medida en que el individuo se repliega sobre el mismo al sentirse incapaz de hablar del Otro y de la sociedad (10). ¿Sería ese el hombre postmoderno? Volveré más adelante sobre el tema.

\section{II}

\section{De la cultura como representación a la práctica como cultura}

Se desprende de las diferentes orientaciones socioantropológicas que se heredaron del siglo XIX y se difundieron en el siglo XX, una preocupación por enmarcar el campo de la cultura con los rasgos de representaciones colectivas tanto a nivel de la sociedad en su conjunto como a nivel de los grupos o clases. Sin duda, esa perspectiva se debe a una concepción de la sociedad europea fuertemente centrada sobre si misma. La idea de Nación y de Estado no es ajena a esa estrechez de vista. La sociedad nacía con las Ciencias humanas de los escombros de la civilización y cultura del Occidente cristiano, exigiendo que la reconozcan más allá de los grandes sistemas filosóficos y teológicos. No es por nada que se difunden en el siglo XIX las famosas explicaciones triádicas del origen moderno de la sociedad. ¿Quien no recuerda la de Auguste Comte? Tres estados precedieron la sociedad positiva, el teológico y el metafísico.

Lo que también chorrea la gran mayoria de las teorías o corrientes socioantropológicos que hemos evocado, es la idea de que la cultura es representación. $Y$ claro lo es como parte del escenario del cual todos somos espectado(10) Denise Lemieux, ed., Traité de la culture, IQRC, Québec, 2002. 
res. En un hermoso libro de sociología, Jean Duvignaud se abocó a definir como la toma de conciencia de la Diferencia pasaba por la representación teatra (11). En el teatro, el actor representa y representa el ciudadano común y corriente como el obrero, el profesional, el aristócrata. Todas las funciones se desdoblan en el escenario. $Y$ lo que se nos presenta delante los ojos es lo que la conciencia desdobla, de la propia realidad. Sin el desdoblamiento no existiria la reflexión sobre la sociedad. Y si en el Medioevo el "auto sacramental" escenifica un paso de la vida de Jesús o alguno de los "misterios" del catolicismo, es para presentar los hechos evangélicos como modelos de vida cristiana o una "verdad teológica" como expresión de una palabra de Fe. En "el gran teatro del mundo", Calderón de la Barca representaba en personajes la idea divina del orden del mundo y de las cosas. La sociedad no era sino la proyección de ese designio sobrenatural. Nótese que en el Medioevo o en el Siglo de Oro, las formas de desdoblamiento, tanto la que provocaba las escenas de la vida de Jesús como la "verdad cristiana" funcionan como modelos o paradigmas para el cristiano, aquél como figura de la vida cotidiana, ésta como acto de fe o de creencia. Los dos tienen un intermediario: la representación. Me atrevería entonces a afirmar que es precisamente la representación que permite, por un lado, conceptualizar la realidad social, y por otro lado, hacer participar al grupo o a la sociedad en la comunión de "misterios" o de "verdades divinas". Subrayaré la idea de participación inspirándome una vez más en los escritos de Fernand Dumont, dándole un sesgo un poco distinto al del maestro.

La idea de participación conlleva la de comunión en la medida en que los individuos o grupos entreactúan porque comparten valores y objetivos. No comulgan necesariamente en los mismos. Sin embargo, pertenecen a una comunidad o a una sociedad que produce y reproduce simbolos o valores que son parte de la vida colectiva. Si compartimos la misma lengua, por ejemplo, conocemos el alcance de los símbolos que empleamos y nos entendemos. Imposible sería la comunicación si no participáramos de la misma definición de los símbolos linguísticos que usamos. Ahora bien, es la cultura en el sen(11) Jean Duvignaud, Sociologie du théatre. Essai sur les ombres colloctives, PUF, Paris, 1965 tido que le daba Dumont, la cultura primera, que nos permite participar en una misma configuración de símbolos a través de los cuales la comunicación es posible. Porque una cosa es compartir y participar, otra la de reconocer las diferencias. En otras palabras, se puede conocer la existencia de un grupo asháninka, no necesariamente la lengua y los símbolos que ellos emplean para comunicarse y participar en una vida colectiva (12) En ese caso, los asháninkas son reconocidos como diferentes como Otro. Pero no comparten conmigo los valores y normas de la sociedad a que pertenezco.

Las características que Dumont otorga a la cultura en sus dos dimensiones, cultura primera y cultura segunda, dependen de una concepción del campo simbólico que privilegia las configuraciones estructurales o las grandes constelaciones simbólicas. De cualquier modo, tanto aplicada a grandes conjuntos más o menos homogéneos como a constelaciones más específicas, la cultura en términos dumontianos es un deudo de las reflexiones que el pensamiento sociológico de corte durkheimiano aportó a la definición de la sociedad. Su originalidad viene del hecho que la cultura es un desdoblamiento de la conciencia que permite conocer la sociedad y definirla como objeto. De ahí su interés. Sin esas constelaciones de símbolos, la conciencia no alcanzaría a desprenderse de si misma y a tomar la distancia que hacen de la sociedad un hecho objetivo y inteligelible.

Ahora bien. Los succesivos cambios introducidos en la representación misma de la sociedad alteraron la propia imagen que las primeras grandes teorías sociológicas nos habían legado a partir del siglo XIX, particularmente en lo que atañe a la cultura. Las nociones y conceptos que las distintas orientaciones nos lejaron sufrieron el impacto de los desarrollos acaecidos en el campo de la ciencia y tecnología. Y las sociedades capitalistas avanzadas transformaron el rumbo de la percepción del mundo y de las cosas. A esos nuevos desafíos corresponde los esfuerzos hechos por Bourdieu. Sus estudios sobre la cultura y el espacio simbólico pretenden demostrar que las diferencias sociales tanto a nivel individual como grupal o de clase, son la consecuencia de distintos trayectos derivados en (12) Fernand Dumont, Le lieu de l'homme. La culture comme distance et memoire, HMH, Montréal, 1968. 
gran parte de la escuela, institución que desempeña un papel preponderante en la definición de los gustos culturales o la inclinación individual hacia ciertas prácticas simbólicas. El origen social es determinante en la herencia de gustos y la apropiación simbólica de bienes y servicios. Sin embargo, Bourdieu no se inscribió en una corriente abiertamente contestataria de las orientaciones sociológicas precedentes tanto a nivel francés como a nivel europeo en general. Si bien es cierto, la importancia que él da a los hechos culturales y al campo simbólico en general, interesa sobre manera a todo aquel que se aboca a definir los fenómenos culturales, no es menos cierto también que muchos de los conceptos vertidos - habitus, campo, espacio, etc. - son parte de una retórica sociológica que cambió de nombre pero no tanto de realidad. Hemos, pues, de buscar en otros autores razones más apropiadas para enfocar las transformaciones que no pocos observadores detectan en el campo contemporáneo de la cultura.

\section{III}

\section{La cultura como producción}

Lo que subrepticiamente las sociedades capitalistas avanzadas fueron derramando como aceite vertido en el oceano fue la idea de que la cultura, o lo que las tradiciones socioantropológicas llaman así, podría no sólo ser contemplado y descuartizado en múltiples discursos y lenguajes más o menos coherentes y uniformes, sino también que los espacios culturales y simbólicos obedecerian a códigos y normas de producción como cualquier otro objeto o bien material. Ahora bien, formular de esa manera lo que puede ser interpretado como la gran revolución en los modos de pensar y enfocar la cultura, es admitir la existencia de cambios profundos en las maneras de ser, de actuar y pensar en la sociedad contemporánea. De hecho, algo ocurrió que sorprendió al propio discurso socioantropológico de los años 1960, aunque no faltaron voces proféticas que lo anunciaron. Elegiré un hecho que marcó el propio lenguaje de las Ciencias humanas. Es el que se conoce como Mayo-1968 en Francia con repercusiones múltiples en distintos países y continentes. Lo escojo adrede porque si algo representó ese movimiento general de masas fue la reivindicación de la cultura en contra de lo que, en ese entonces, se tenía como el establishement intelectual y académico autoritario, normativo y en muchos casos, cavernario. $O$ sea, en olas succesivas, los movimientos estudiantiles primero, luego los grupos sindicales y partidos políticos, rompieron con las normas establecidas y crearon los lazos de solidaridad que le permitieron aunar distintas fuerzas sociales en una lucha común. A primera vista parecia que se trataba de rebeliones estudiantiles sin mayor proyección sobre el conjunto de la sociedad. En el transcurso de pocas semanas los dirigentes que hoy día militan en partidos europeos, cambiaron el sentido juvenil de programas académicos en un objetivo político y social de envergadura. La sociedad pudo expresarse y darse el lujo da hablar sobre sus deseos y angustias. $Y$ de paso nació una nueva cultura.

Bien vistas las cosas, los eventos que marcaron ese fin de la década de oro de las rebeliones estudiantiles europeas en el siglo $X X$, no eran totalmente novedosos ni fruto del asar. Se veía venir. Lo anunciaban otras mobilizaciones en Estados Unidos con fuerte color racista, apoyadas por el Black Power y algunos líderes carismáticos. Y en Berkeley (California) enseñaba Herbert Marcuse (1898-1979) que acabó por ser uno de los más destacados intelectuales de esos frentes insurgentes. Tenía su razón de ser porque habia sido él más que ningun otro, el baluarte de los que cuestionaban la sociedad contemporánea y denunciaban sus nuevas formas de organización y pensamiento. El hombre unidimensional (1964) era el producto de la cultura actual, un hombre racional que quiso someter la naturaleza y acabó por ser dominado por ella. Y siguiendo los pasos de la Escuela de Frankfurt, Marcuse arremete contra la implacable ley de la "razón técnica" la cual es la característica occidental de la evolución de las sociedades capitalistas avanzadas, sean ellas centralizadas como en la experiencia soviética, sean ellas liberales como en los Estados Unidos. No hay salida posible para el hombre contemporáneo, porque la "razón técnica" le impide de acceder a los medios que lo harian libre. De esa manera, el espacio de la cultura es también producto de esa dominación racional técnica, la cual se hace presente en las grandes manifestaciones de mass media y en lo que pronto UNESCO consacrará con una expresión lapidar, 'industrias culturales" (1968). 
No dejan de ser inquietantes las transformaciones denunciadas por Marcuse en un contexto critico que fue compartido por Horkheimer, Adorno y Benjamin, los cuatro con destinos personales e intelectuales marcados por el pesimismo frente a las sociedades capitalistas avanzadas. Todos ellos consacraron lo más importante de sus disquisiciones al campo de la cultura. Y precisamente coincidieron en sus acerbas críticas de todo lo que olía a "industria cultural". Según ellos, transformados en productos, los objetos culturales son manipulados y orientados hacia la dominación del hombre. Sin embargo, Marcuse reconoció que uno de los caminos de salida posible frente a la incapacidad de la sociedad contemporánea de tomar la libertad perdida en los procesos de toma de conciencia de la "razón técnica" que heredó de la llustración era precisamente el arte. En esas expresiones culturales intuía él la condescendencia de la sociedad burguesa que, propensa al totalitarismo, sería aún capaz de tolerar ciertos excesos o extravios de la libertad del artista. La respuesta no es muy original, menos aún, crítica. Manifiestamente es una herencia burguesa. Sea lo que sea, los años que se siguieron a la Segunda Guerra Mundial fueron decisivos para la globalización de los procesos culturales. La presencia de la radio, de la televisión, del cine en la vida cotidiana se ha hecho sentir cada vez más. Y lo que la Escuela de Frankfurt temía y criticaba acaeció y con creces. $Y$ no necesariamente en términos de "aldea global" como lo formuló MacLuhan, sino más bien como una difusión masiva de símbolos en todos los espacios societales, en todos los continentes. A eso llegamos en nuestros días.

\section{IV \\ Los procesos culturales}

Lo que hoy dia nos parece hasta cierto punto natural y como parte de nuestros hábitos de vida, es la consecuencia de un proceso que desembocó en la profusión de imágenes y figuras salidas no tanto de un taller artesanal cuanto de una red industrial que dibuja y produce objetos y bienes aptos para el consumo masivo. Por consiguiente, los procesos culturales se rigen no por normas estéticas elitistas sino más bien por las reglas del mercado que analiza y satisface los deseos de las masas. Vuelvo sobre el ejemplo de Bourdieu que ilustra las di- ferencias de gusto. En sus investigaciones sobre el arte y la "distinccion", es decir sobre los "gustos distinguidos" o lo que podría llamarse "los gustos de gente fina o pituca" no corresponde a esa orientación masiva (13). Sin embargo, el sociólogo francés comprendió algo que merece ser mencionado: hay una radical diferencia entre gusto distinguido y gusto popular debido a dos órdenes de hechos. El primero tiene su origen en el espacio de representación y el segundo, en las propias condiciones de vida, enraizadas en lo que él llamó habitus, es decir en las configuraciones simbólicas heredadas de un contexto social y cultural. El "gusto popular" no alcanza a expresarse en términos culturales elitistas. Le faltan símbolos y sobre todo capacidad para entender lo que realmentre acaece en el mundo del "gusto burgués".

En el contexto contemporáneo de las sociedades capitalistas avanzadas, los procesos culturales corresponden a intervenciones directas de los actores industriales en los espacios de representación. No son simplemente las instituciones que ordenan la sociedad que secretan símbolos y los jerarquizan. No. Hay una producción conciente de imágenes que pueblan el imaginario popular. Quizá el ejemplo más flagrante es el de la televisión a que ya me referí y el cinema. Y Hollywood fue pionera en ese campo. Allá por los años 1920 un grupo de empresarios, cuatro si mal no recuerdo, se lanzaron en la producción cinematográfica. $Y$ con intenciones más o menos precisas de difundir imágenes y relatar hechos fantásticos que servirian no sólo para distracción de las masas sino también para orientarlas en ciertas opciones y decisiones de la vida cotidiana. O sea de ahí en adelante, las industrias a que los inventos de los hermanos Lumière habian dado lugar, llenaban funciones que correspondian en las sociedades tradicionales a grupos sociales más o menos identificados con el espacio simbólico. Hablo, por ejemplo, de las instituciones religiosas cuya función primera era precisamente la de definir las figuras y signos relacionados con el imaginario, ayudandándo a precisar sus reglas e interviniendo en su diseño y definición. Al llenar las paredes de las iglesias con pinturas, al poblar los altares mayores con retablos donde se escenificaban vidas de santos o de la Virgen o de Je-

(13) Pierre Bourdieu, La distinction. Critique sociale du jugement, Minuit, Paris, 1979. 
sús, el catolicismo proporcionaba al imaginario popular las imágenes o figuras con que él nutría sus propias fantasías.

Al contrario de lo que ocurría en las sociedades tradicionales, hoy día no se podria hablar de una institución o de instituciones que en forma casi exclusiva proporcionan a la sociedad las imágenes o símbolos para su propio consumo. Hollywood no es una institución. Sin embargo, en las tareas y funciones que ella se atribuyó a si misma, existía la deliberada voluntad de intervenir en el imaginario y de poblarlo con las imágenes y símbolos que todos le reconocemos. Y hoy dia, figuras tan populares como Marilyn Monroe o Greta Garbo, o personajes tan conocidos como Rambo, no son productos específicos de una institución que define un campo social. Unas y otro fueron creados por empresas que se dedican a la producción de figuras fantásticas e imaginarias. Lo mismo ocurrió con los personajes de Disneylandia. El imaginario infantil se llenó con sus hazañas. Son ellos que compiten con los tradicionales símbolos religiosos o con las figuras que las instituciones sociales se encargaban de dibujar. De esa manera, la imagen del padre o madre no es sólo la que ofrece la relación directa y cotidiana del entorno familiar, sino también la que divulgan una pelicula o un personaje famoso de una telenovela.

No cabe, pues, la menor duda, que los procesos culturales contemporáneos son radicalmente distintos de sus congéneres antiguos. Y el cambio no es sólo de forma, menos aun de aparencia. Son procesos culturales que modifican las propias estructuras societales y las reglas de juego de las clases o grupos sociales. Si Hollywood crea y difunde sus propias figuras paradigmáticas, diseña el personaje de un héroe y lo pone en circulación a nivel mundial, compite con los modelos que las instituciones familiares o religiosas o políticas enuncian. La gran diferencia es que la familia, la Iglesia, un partido no son, hablando con propiedad, una empresa de negocios, mientras Hollywood y sus proprietarios lo son, en un contexto de corte capitalista y en un medio social y financiero que privilegía las ganancias del capital. $Y$ eso es toda la diferencia del mundo.

\section{V \\ El consumo cultural}

La expresión "consumo cultural" es la más adecuada para caracterizar los fenónemos a que acabamos de hacer referencia. Así lo entendieron también los que, desde distintos puntos de vista, vienen trabajando en el tema. Sunkel puede ser un excelente ejemplo del esfuerzo llevado a cabo en un contexto latinoamericano aunque muy sesgado por los estudios parciales que edita. No importa. Es un aporte interesante en la medida en que difunde un intento de comprensión de ciertos hechos culturales que no se explican sino en el contexto de producciones masivas. Una vez más, la televisión es el medio estudiado. Su importancia no esta en duda. Sin embargo, hay que tener un espacio de producción cultural más amplio para que la idea de consumo cultural latinoamericano sea realista. En Sunkel no lo es (14).

García Canclini define el consumo como "el conjunto de procesos socioculturales en que se realizan la apropiación y los usos de los productos" (15). A partir de ahí ofrece varios modelos de consumo: "lugar de reproducción de la fuerza de trabajo y de expansión del capital"; "lugar donde las clases y los grupos compiten por la apropiación del producto social"; "lugar de diferenciación social y distinción simbólica"; "sistema de integración y comunicación"; "escenario de objetivación de los deseos"; "proceso ritual". Todos estos aspectos mencionan una dimensión señalada por diferentes estudios socioantropológicos. De hecho, el acto de consumir reúne diferentes líneas del quehacer cotidiano y expresa igualmente una parte de las relaciones sociales, ya sean de orden estructural, ya sean de orden individual. Se habla, por ejemplo, de la satisfacción de un deseo o de una necesidad o de la inclinación casi natural por la apropiación de un objeto. Asimismo, no faltan casos de consumo ritual como los que estudió Marcel Mauss analizando las sociedades del Oeste americano (16). Ahi se practicaba lo que se llamaba el "potlach" o la donación hasta el agotamiento de los

(14) Guillermo Sunkel, coord., El consumo cultural en América latina, Convenio Andrés Bello, Bogotá, 1999.

(15) Néstor García Canclini, "El consumo cultural: Une propuesta tedrica", Guillermo Sunkel, op. cit., Convenio Andrés Bello, Bogotá, 1999: 34.

(16) Marcel Mauss, "Essai sur le don, forme et raison de l'échange dans les soclêtés archaiques", Année sociologique, 1923-1924, 145-279. Cf.: Marcel Fournier, Marcel Mauss, Fayard, Paris, 1994. 
bienes colectivos. En el gesto de donar se obligaba ritualmente al donatario a actuar reciprocamente. Y cuanto más se donaba más prestigio acumulaba a los ojos de la sociedad.

La dimensión socioantropológica también fue objeto de un excelente estudio de Arjun Appadurai sobre el consumo. No hace referencia al artículo de Mauss sobre el don. Sin embargo, recurre a un otro texto del antropólogo francés, sobre "técnicas del cuerpo". Según Appadurai, "el cuerpo reclama disciplinas de repetición o, por lo menos, disciplinas periódicas" (17), siendo los ritos de pasaje uno de los hechos más característicos de las sociedades tanto antiguas como contemporáneas. En esos momentos especiales, el consumo adquiere fuerza de ley y actúa como gesto de apropiación de bienes y servicios en gran escala. Las fiestas de Navidad, por ejemplo, son una de las fechas en que más se consume y para muchos individuos, son los dias del año en que se les agotan las ganancias ahorradas a lo largo de varios meses. Frecuentes también, y marca de un consumo suntuario, son las fiestas de "quince años" en que las adolescentes ganan derecho de ciudadania y se presentan a la sociedad como futuro objeto de pretención matrimonial. Analizando varios casos en diferentes sociedades, Appadurai distingue tres modelos en que se dan formas organizadas de consumo: la interdicción, la ley suntuaria y la moda (18). El paso de un modelo a un otro no es siempre fácil de definir. Pero la revolución en el consumo ocurre en forma generalizada cuando se pasa de la ley suntuaria al regimen de la moda (19).

Tanto García Canclini como Appadurai dan muestras de un sesgo antropológico muy marcado, el primero más propenso a emplear algunas nociones del "marxismo vulgar", el segundo más amplio y agudo. Al examinar los autores en que ellos basan sus disquisiciones, se nota la importancia de algunas de sus lecturas. Por ejemplo, el peso de los escritos de Bourdieu, nomeadamente La distinccion y él de los ensayístas franceses, Baudrillard y los de los recordados De Certeau y Roland Barthes, todos ellos más superficiales que el clásico en la materia, Miguel Bajtin. Pero, los cambios ocurridos [17] Arjun Appadurai, La modernidad desbordada. Dimensiones culturales de la globalización. Trilce/FCE, México, 2001: 82

(18) Arjun Appadurai, op cit., Trilce/FCE, México, 2001: 86

(19) Arjun Appadurai, op cit. Trilce/FCE, México, 2001: 87 en las sociedades contemporáneas son demasiado rápidos y tan diversificados y hasta tan novedosos que no siempre es fácil acertar con las dimensiones a tenerse en cuenta en el análisis de los hechos. Tanto los mencionados autores como otros a que no he hecho referencia se ubican en un contexto de cultura burguesa o aristocrática, quizá suntuaria. Bajtin se interesó por la cultura popular en tiempos de Rabelais. Sin embargo, el consumo cultural de masas no responde a los mismos criterios ni tampoco a los mismos entornos socioculturales en que él desarrolló sus estudios. Sobre ese punto las reflexiones de Appadurai me parecen más originales. Para él, el consumo es "el intervalo entre dos períodos de producción" (p. 93). El tiempo libre, por ejemplo, es aquél en que el trabajador organiza sus vacaciones para "consumir" en forma acelerada lo que le queda de momentos de entretenimiento o de lazer. Es en ese tiempo también que se consume lo máximo de bienes culturales: viajes de recreo, visitas a monumentos o sitios históricos y arqueológicos, en un palabra, es el tiempo de la imaginación y de la fantasía. Lo que se llama turismo cultural es eso precisamente. ¿No es verdad, por ejemplo, que muchos turistas que vienen a Machu Picchu son atraídos por "energías vitales", "espacios siderales" y otros productos de la imaginación?

\section{VI \\ EI horizonte cultural del efímero y del placer}

Entre las muchas sugerencias de Appadurai, hay algunas que se refieren al consumo como el reino del efímero. Los productos consumidos en las sociedades contemporáneas son, en su gran mayoria, perecibles. La moda es un excelente ejemplo de una estética del efímero. Los modelos varían con las estaciones y cada vez más los productos expuestos y consumidos son deleznables. Más aún: los grandes maestros de la moda emplean cada vez más prendas livianas y materiales con usos múltiples y fugaces. ¿Y qué decir de la publicidad? Su lenguaje es el espacio favorito de los productos efímeros, de las imágenes volátiles, de los sonidos y figuras perecederos. Los grupos de música pop en sus diferentes versiones, se afanan en presen- 
tar sus producciones como una luz que se prende y apaga en un instante intenso pero fugaz. Todo se puede desechar. $Y$ en ese sentido conumir no sólo es apropiarse de un bien sino también hacer la experiencia del efímero.

Lo que suele llamarse industrias culturales puede también ser objeto de las mismas reflexiones. Las artes visuales, la pintura, la arquitectura y otras expresiones artisticas se inscriben en esa concepción de lo espontáneo e instantáneo. Las imágenes y formas empleadas en muchos espacios artisticos crean esa sensación del efímero. Y más aún la producción cinematográfica a la que se ha de añadir toda la industria video y, en general, la de las nuevas tecnologias. Todas ellas están impregnadas de ese casi inconciente sentimiento de volatilidad de los objetos y de las imágenes. La propia textualidad de la escritura se vuelve efimera en la pantalla de una computadora, en la forma estilística de una novela, en el diseño gráfico. El efímero es la expresión de un acto instantáneo que no tiene futuro, que nace y muere en el presente.

En cuanto al placer que algunos autores suponen ser el motor del consumo en general, y en particular, del el consumo cultural (20), me parece interesante discutirlo también en base a una reflexión de Appadurai: "(...)el tipo de placer que se halla en el centro del consumo moderno no es el placer de la tensión entre fantasia y la utilidad (...), o la tensión entre el deseo individual y las disciplinas colectivas (...), aun si tales contrastes son relevantes para una explicación más amplia del consumismo moderno. El tipo de placer que fue inculcado en los sujetos que actúan como consumidores modernos va a encontrarse en la tensión entre la fantasia y la nostalgia, donde el presente es representado como si ya hubiera pasado. Esta inculcación del placer de lo efímero yace en el corazón del disciplinamiento del consumidor moderno" (21).

Hay varias dimensiones en esa idea, siendo una de ellas la que explora la publicidad. Consiste ésta en convencerte que lo que se está mirando en una situación presente produce en el individuo una nostalgia del pasado. ¿Quién no conoce los "colores de Benetton"?
Los cuatro hermanos italianos construyeron un imperio comercial de prendas de vestir, ayudados por una inteligente campaña publicitaria que tiene una historia digna de estudiarse. Desde los campos y rebaños que la empresa compró en Patagonia, Argentina hasta la producción en cadena de ropa frágil y fácil de vestir, hay una trama de acciones y productos que atraen los jóvenes y con los jóvenes, los adultos. Hace unos años, un famoso anuncio publicitario de Benetton escandilzó. Se mostraba a un sacerdote católico con su sotana y sombrero tradicional, en negro pronunciado, al lado de una joven doncella, de pulcra belleza, con un vestido blanco muy tradicional también, insinuando matrimonio. EI negro y el blanco creaban una tensión de colores y la situación social, un contraste simbólico. Retomando la idea de Appadurai, se podría decir que el presente que ahí se expone es nostálgico, porque el público se da la fantasía de creer que esos colores son los de la moda. Sin embargo, como también subraya el autor, nadie alcanza los objetos que ahí se exponen. En otras palabras, el consumo que la mirada sugiere produce la nostalgia del propio presente, a través de un bien que de hecho nunca existió y del cual muy pocos se pueden apropiar.

\section{VII \\ La desterritorialización de la cultura}

$Y$ a modo de nota final, trataré de un tema que es de la mayor importancia: la desterritorialización de la cultura. Quizá sea ese hecho una de las consecuencias más notables de la globalización. Con la circulación de personas por todos los continentes, con la difusión mundial de productos, bienes y servicios a través de los mass media, con las facilidades de acceso a la información y el uso de la comunicación via internet, la velocidad de los los intercambios entre individuos a nivel planetario se volvió un hecho común y corriente. En el campo de las industrias culturales, el cinema, la televisión y la radio crean los simbolos e imágenes y las siembran en todo el mundo. No hay limites para la información, y tampoco los hay para el imaginario. Por consiguiente, la cultura como horizonte no se restringe a un espacio cultural preciso sino más bien recibe el impacto de múltiples fuentes y diferentes y variados lenguajes. Michael Jackson es mundialmente conocido. Las peliculas 
hindúes se proyectaban en Cuzco en los años 1980 y comovian a esa población modesta, de semblante cholo. O sea las industrias culturales difundieron en Ocidente y Oriente sus imágenes y simbolos y con tanta fortuna que lo que creiamos local se volvió universal. El horizonte cultural no tiene espacio ni tiempo fijo.

Las migraciones acentuaron aún más ese nuevo fenómeno. Grandes masas de migrantes llegaron en la segunda mitad del siglo XX a Américal del Norte, mientras la Unión Europea recibia ultimamente millones de trabajadores. Se podria llamar a esos fenómenos globales, procesos de mestisaje. Sin embargo, hay algo más profundo. Esos procesos sociales dan lugar a lo que García Canclini llamó, muy impropiamente, "culturas híbridas" (22). De hecho, de híbrido no tienen nada. Ocurre, sin embargo, que los procesos culturales tienen esa característica, es decir, la de asumir símbolos e imágenes para elaborar lenguajes, producir configuraciones imaginarias. No se trata, pues, de productos híbridos sino más bien de la creación y producción contínua de espacios culturales.

Henrique Urbano

Instituto de Investigación

Escuela Profesional de Turismo y Hotelería Universidad de San Martín de Porres 